\title{
ВЛИЯНИЕ ЭМПАГЛИФЛОЗИНА И L-ОРНИТИНА L-АСПАРТАТА НА ПОВЕДЕНЧЕСКО-КОГНИТИВНЫЕ ФУНКЦИИ И ФИЗИЧЕСКУЮ РАБОТОСПОСОБНОСТЬ ПРИ ЭКСПЕРИМЕНТАЛЬНОМ СТЕАТОГЕПАТИТЕ
}

В. А. Приходько $1 凶$ Ю. И. Сысоев ${ }^{1,2}$, М. А. Поверяева ${ }^{1}$, А. В. Бунят ${ }^{1}$, В. Е. Карев ${ }^{3}$, Д. Ю. Ивкин ${ }^{1}$, Д. С. Суханов ${ }^{1}$, Е. Б. Шустов ${ }^{1}$,

С. В. Оковитый

${ }^{1}$ Санкт-Петербургский государственный химико-фармацевтический университет, Санкт-Петербург, Россия

2 Институт трансляционной биомедицины, Санкт-Петербургский государственный университет, Санкт-Петербург, Россия

${ }^{3}$ Детский научно-клинический центр инфекционных болезней ФМБА России, Санкт-Петербург, Россия

Неалкогольная жировая болезнь печени (НАЖБП) - хроническое заболевание, характеризующееся не только изменениями углеводного и липидного обменов, но и рядом психоневрологических нарушений, включая тревожно-депрессивные расстройства, ухудшение памяти и астенический синдром. Большинство фармакологических исследований направлено на оценку способности препаратов восстанавливать биохимические функции и гистоморфологическую картину печени при НАЖБП; их влияние на течение сопутствующих нарушений изучают редко. Целью работы было оценить влияние эмпаглифрлозина и L-орнитина L-аспартата (OA) на поведение, память и физическую работоспособность мышей линии C57BL/6 при моделировании НАЖБП (6-месячная «западная диета» с еженедельным введением тетрахлорметана). Данная модель вызывает у животных изменение поведения (снижение скорости передвижения на 38 и 35\%, p< 0,01; увеличение частоты стоек на 432 и 279\%, p< 0,05 и др.), ухудшение долговременной памяти (время поиска в «Лабиринте Барнс» возрастало на 108\%, число ошибок — на 439\%, $p<0,05$ ), а также снижение физической работоспособности (время вынужденного плавания сократилось на 50\%, $p<0,05$ и др.). Оба препарата при введении во время диеты снижали тревожность (эмпаглифлозин: число грумингов возросло на 160\%, $p<0$, 05 и на 2173\%, $p<0$ 0,01; время в белой зоне черно-белой камеры - на 275\%, p < 0,05 и др.; ОА: время в открытых рукавах лабиринта увеличилось на 267\%, $p<0,05)$ и способствовали сохранению памяти у мышей с НАЖБП. Особенностью ОА было повышение физической работоспособности животных (время вынужденного плавания увеличилось на 106\%, p < 0,05 и др.). Таким образом, эмпаглифлозин и ОА могут положительно влиять на поведенческие и когнитивные функции, а также снижать выраженность астенического синдрома при НАЖБП.

Ключевые слова: неалкогольная жировая болезнь печени, стеатогепатит, когнитивные нарушения, физическая работоспособность, эмпаглифлозин, L-орнитина L-аспартат

Финансирование: работа проведена в рамках проекта Санкт-Петербургского государственного университета №: 51134206.

Вклад авторов: В. А. Приходько - анализ литературы, проведение экспериментов; анализ, статистическая обработка и интерпретация данных; подготовка рукописи и иллюстраций. Ю. И. Сысоев - планирование исследования, анализ литературы, проведение экспериментов; анализ, статистическая обработка и интерпретация данных; подготовка рукописи и иллюстраций. М. А. Поверяева - проведение экспериментов; А. В. Бунят планирование исследования, проведение экспериментов; В. Е. Карев - анализ и интерпретация данных, подготовка рукописи и иллюстраций; Д. Ю. Ивкин - планирование исследования, анализ литературы; Д. С. Суханов - планирование исследования, анализ и интерпретация данных, подготовка рукописи; Е. Б. Шустов и С. В. Оковитый - планирование исследования; анализ литературы; анализ и интерпретация данных; подготовка рукописи.

Соблюдение этических стандартов: все эксперименты проводили в соответствии с принципами Базельской декларации, Приказом Минздрава РФ от 01.04.2016 № 199н «Об утверждении правил надлежащей лабораторной практики» и рекомендациям биоэтической комиссии ФГБОУ ВО СПХФУ Минздрава России. Животных содержали в стандартных условиях вивария с соблюдением нормативных требований к питанию и освещению.

$\triangle$ Для корреспонденции: Вероника Александровна Приходько

ул. Краснопутиловская, д. 76, к. 2, лит. А, г. Санкт-Петербург, 196247; veronika.prihodko@pharminnotech.com

Статья получена: 22.05.2020 Статья принята к печати: 08.06.2020 Опубликована онлайн: 20.06.2020

DOI: $10.24075 /$ vrgmu.2020.034

\section{EFFECTS OF EMPAGLIFLOZIN AND L-ORNITHINE L-ASPARTATE ON BEHAVIOR, COGNITIVE FUNCTIONS, AND PHYSICAL PERFORMANCE IN MICE WITH EXPERIMENTALLY INDUCED STEATOHEPATITIS}

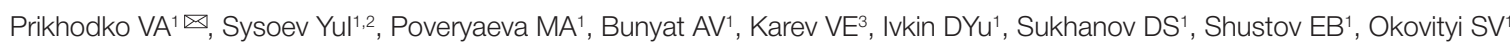

1 Saint Petersburg State Chemical and Pharmaceutical University, Saint Petersburg, Russia

${ }^{2}$ Institute of Translational Biomedicine, Saint Petersburg State University, Saint Petersburg, Russia

${ }^{3}$ Pediatric Research and Clinical Center for Infectious Diseases of FMBA, Saint Petersburg, Russia

Non-alcoholic fatty liver disease (NAFLD) is a chronic condition characterized by disturbed carbohydrate and lipid metabolism and often complicated by psychoneurological symptoms, including anxiety, depression, memory deficit, and asthenia. Most studies of pharmacotherapy candidates for NAFLD focus on the ability of the tested drugs to restore the biochemical functions and morphology of the liver while their potential effects on the co-existing conditions remain overlooked. The aim of this paper was to investigate the effects of empagliflozin and L-ornithine L-aspartate (OA) on behavior, memory, and physical performance in C57BL/6 mice with experimentally induced NAFLD (6 months of a Western diet + weekly carbon tetrachloride injections). The disease affected animal behavior (locomotion speed decreased by $38 \%$ and $35 \%, p<0.01$; rearing increased by $432 \%$ and $279 \%, p<0.05$ etc.), induced long-term memory deficit (latency to find the target box increased by $108 \%$ in the Barnes maze, the number of errors increased by $439 \%, p<0.05$ ), and compromised physical performance (swimming time in the forced swim test dropped by $50 \%, p<0.05$ etc.). When administered during the high-calorie diet period, both drugs reduced anxiety (empagliflozin: the number of grooming bouts rose by $160 \%, p<0.05$ and $2173 \%, p<0.01$; time spent in the light compartment in the light/dark box test increased by $275 \%$, $p<0.05$, etc.; OA: time spent in the open arms of the maze increased by $267 \%, p<0.05$ ), and promoted memory retention in mice with NAFLD. OA improved physical performance (swimming time in the forced swimming test improved by $106 \%, p<0.05$, etc.). Thus, empagliflozin and OA can have a beneficial effect on cognitive functions, as well as behavior, and ameliorate asthenia in NAFLD.

Keywords: non-alcoholic fatty liver disease, steatohepatitis, cognitive disorders, physical performance, empagliflozin, L-ornithine L-aspartate

Funding: this work was part of the Saint-Petersburg State University project № 51134206.

Author contribution: Prikhodko VA analyzed the literature; conducted the experiments; participated in statistical analysis and interpretation of the obtained data; wrote the manuscript and prepared the figures. Sysoev Yul planned the study; analyzed the literature; conducted the experiments; participated in statistical analysis and data interpretation; wrote the manuscript and prepared the figures. Poveryaeva MA conducted the experiments; Bunyat AV planned the study; conducted the experiments; Karev VE analyzed and interpreted the obtained data; wrote the manuscript and prepared the figures; Ivkin DYu planned the study; analyzed the literature; Sukhanov DS planned the study; analyzed and interpreted the obtained data; wrote the manuscript; Shustov EB, Okovityi SV planned the study; analyzed the literature; analyzed and interpreted the obtained data; wrote the manuscript.

Compliance with ethical standards: the experiments were conducted in compliance with the Basel Declaration, the Order № 199 on the Principles of Good Laboratory Practice of the Ministry of Healthcare of the Russian Federation dated April 01, 2016, and the recommendations of the Bioethics Committee of Saint Petersburg State Chemical and Pharmaceutical University. The animals were housed in a vivarium under standard controlled laboratory conditions.

$\square$ Correspondence should be addressed: Veronika A. Prikhodko

Krasnoputilovskaya, 76, k. 2, lit. A, Saint Petersburg, 196247; veronika.prihodko@pharminnotech.com

Received: 22.05.2020 Accepted: 08.06.2020 Published online: 20.06.2020

DOI: $10.24075 /$ brsmu.2020.034 
Неалкогольная жировая болезнь печени (НАЖБП) это хроническое заболевание, при котором происходит избыточное накопление липидов в гепатоцитах в отсутствие повреждающего действия алкоголя и других токсических веществ. Возникновение и развитие НАЖБП тесно связано с нарушениями углеводного и липидного обменов, ожирением и инсулинорезистентностью. По современным оценкам, до 25\% мирового населения страдают НАЖБП, что делает это заболевание основной причиной хронической патологии печени [1, 2].

Помимо метаболических нарушений, большое внимание специалистов привлекают тревожнодепрессивные расстройства, астения и когнитивные нарушения, ассоциированные с НАЖБП [3-5]. Так, в одном из исследований у 53\% больных НАЖБП была обнаружена субклиническая депрессия и у 14\% - клиническая [6]. Стоит отметить, что у таких пациентов раздражительность и перепады настроения часто сопровождаются повышенной утомляемостью и хронической усталостью [3]. Ряд исследователей полагают, что когнитивные нарушения осложняют течение НАЖБП практически у всех больных, из которых половина испытывают их в легкой форме, а другая половина - в среднетяжелой или тяжелой [4].

Основные цели лечения НАЖБП - устранение факторов развития, уменьшение проявлений и предупреждение прогрессирования болезни [2, 7]. К лекарственным препаратам, применение которых может быть показано у больных НАЖБП наряду с диетой и физической нагрузкой, относят гиполипидемические и гипогликемические средства, а также гепатопротекторы $[2,7]$. Их эфффективность в качестве средств коррекции метаболических нарушений изучена достаточно подробно, но оценке возможности их применения при психоневрологических нарушениях на фоне НАЖБП посвящено весьма ограниченное число работ [8,
9]. В связи с этим целью настоящего исследования стала оценка влияния эмпаглифлозина и L-орнитина L-аспартата на поведение, когнитивные функции и физическую работоспособность мышей линии C57BL/6 при моделировании у них НАЖБП.

\section{МАТЕРИАЛЫ И МЕТОДЫ}

Исследование выполнено в Санкт-Петербургском государственном химико-фармацевтическом университете на 52 трехмесячных инбредных мышах-самцах линии C57BL/6 со средней массой тела 23 г, полученных из ФГУП «ПЛЖ Рапполово» (Ленинградская область). Животные получали корм «Полнорационный комбикорм для лабораторных животных» (ООО «Лабораторкорм», РФ) и воду, соответствующую требованиям ГОСТ 287482 «Вода питьевая» (исключая период высококалорийной диеты). Доступ к корму и воде был обеспечен ad libitum. Выбор животных этой линии обусловлен развитием у них метаболических и поведенческо-когнитивных изменений на фоне высокожировой диеты [10, 11]. По окончании 14-дневного периода адаптации мыши были рандомизированы на четыре экспериментальные группы: 1-я группа - интактные животные («Интакт»; $n=10)$, 2-я - контроль без лечения («Контроль»; модель НАЖБП, $n=$ 14), 3-я - НАЖБП + эмпаглифрлозин («ЭМПА»; Джардинс ${ }^{\circledR}$, 2 мг/Кг; $n=14)$, 4-я - НАЖБП + L-орнитина L-аспартат («ОА»; Гепа-Мерц ${ }^{\oplus}, 1,5$ г/кг, $n=14$ ). Исследуемые препараты вводили внутрижелудочно с использованием зондов в течение всего эксперимента раз в день, контрольная и интактные группы получали эквиобъемные количества 0,9\%-го раствора хлорида натрия.

НАЖБП (стеатогепатит) моделировали, используя сочетание «западной» диеты (western diet) и внутрибрюшинного введения тетрахлорметана $\left(\mathrm{CCl}_{4}\right)$

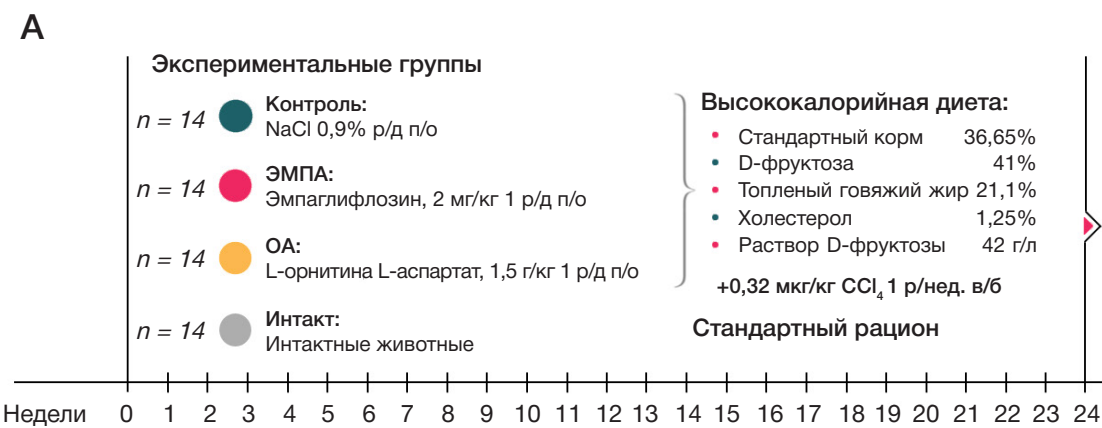

Б

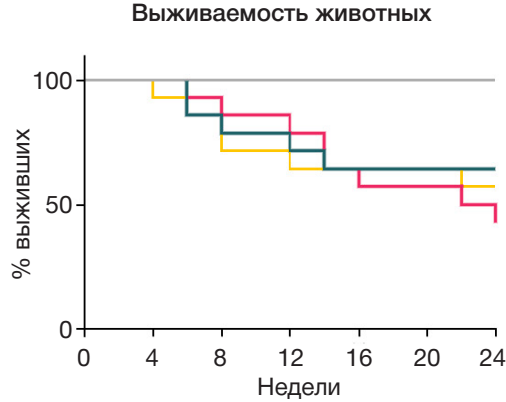

B

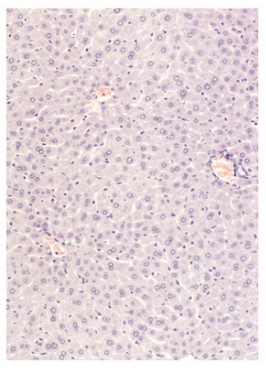

1

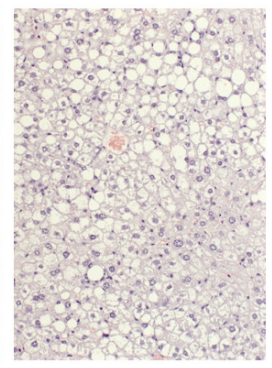

2

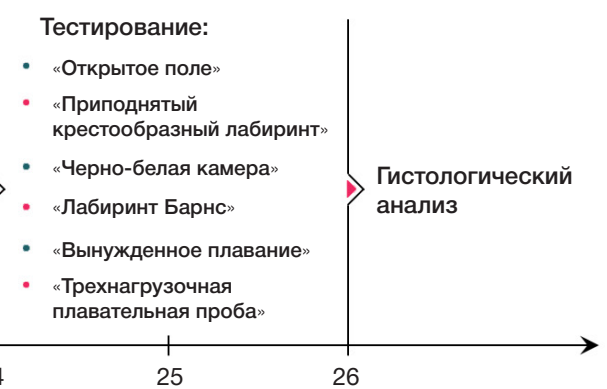

25

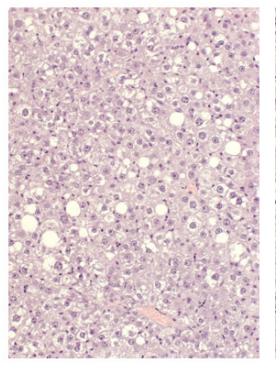

3

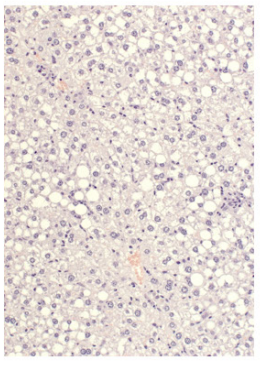

4

Рис. 1. А. Описание модели НАЖБП, тестируемых групп и схема эксперимента. р/д - раз в день, р/нед. - раз в неделю, п/о - перорально, в/б внутрибрюшинно. Б. Динамика выживаемости животных. В. Гистоморфологическая картина печени животных экспериментальных групп. 1 (Интакт) - нормальная структура ткани печени; 2 (Контроль) - морфологические признаки НАЖБП: выраженная крупнокапельная жировая дистрофия гепатоцитов, выраженная баллонная дистрофия гепатоцитов, очаговая инфильтрация полиморфноядерными лейкоцитами паренхимы печени; 3 (ЭМПА) - морфологические признаки НАЖБП: слабо выраженная крупнокапельная жировая дистрофия гепатоцитов, слабо выраженная баллонная дистрофия гепатоцитов, патологическая клеточная инфильтрация паренхимы печени отсутствует; 4 (ОА) - умеренно выраженная крупнокапельная жировая дистрофия гепатоцитов, умеренно выраженная баллонная дистрофия гепатоцитов, умеренно выраженная полиморфноклеточная инфильтрация паренхимы печени. А, Б, В, Г - окраска гематоксилином и эозином, ×200 
(рис. 1А). Группы «Контроль», «ЭМПА» и «ОА» в течение 6 месяцев находились на высококалорийной диете (ВКД) следующего состава: 36,65\% стандартного корма + $21,1 \%$ топленого говяжьего жира + 41\% D-фруктозы + 1,25\% холестерола. В качестве питья животные указанных групп получали раствор D-фруктозы с концентрацией 42 г/л. Еженедельно в течение всего периода ВҚД животным указанных групп вводили внутрибрюшинно $\mathrm{CCl}_{4}$ в дозе 0,32 мкг/Кг массы тела [12]. Интактные мыши на протяжении всего периода получали стандартный корм и питьевую воду без добавок.

По истечении периода ВКД поведение животных оценивали в тестах «Открытое поле» (ОП), «Черно-белая камера» (ЧБК) и «Приподнятый крестообразный лабиринт» (ПКЛ) (НПК «Открытая наука»; Россия) с использованием системы видеорегистрации VideoMot2 (TSE Systems; Германия).

Для оценки краткосрочной и долгосрочной памяти мышей тестировали в «Лабиринте Барнс» (ЛБ) (НПК «Открытая наука»; Россия) [13]. Обучение животных проводили ежедневно 4 раза в течение 4-х дней; на 5-й и 12-й дни осуществляли контрольное тестирование. В процессе обучения и тестирования учитывали время нахождения target box (c), а также число совершенных ошибок.

Через два дня после проведения поведенческих тестов фризическую работоспособность животных оценивали с помощью плавательных тестов «Вынужденное плавание» (ВП) с грузом 7,5\% от массы тела и «Трехнагрузочная плавательная проба» (ТПП) [14, 15]. Регистрацию времени плавания в ТПП вели в 3-х временных точках: исходно, через 5 и через 45 мин после начала тестирования.

Для определения структурных изменений в печени выполняли гистологическое исследование. Образцы ткани печени после фиксации 10\%-м нейтральным формалином подвергали дегидратации и обезжириванию с использованием изопропанола, имбибиции парафином по общепринятой методике. Из парафиновых блоков изготовляли срезы толщиной 4 мкм, помещали на предметные стекла, окрашивали гематоксилином и эозином и заключали под покровные стекла. Изучение гистологических препаратов осуществляли в проходящем свете с качественной оценкой жировой и белковой (баллонной) дистрофии гепатоцитов, а также патологической клеточной инфильтрации паренхимы печени [2, 16].

Статистическую обработку полученных данных проводили с использованием пакета программного обеспечения GraphPad Prism 8.0.2 (GraphPad Software; CША). Осуществляли проверку нормальности распределения количественных признаков с использованием W-критерия Шапиро-Уилка. При нормальном распределении количественных признаков значимость различий оценивали с помощью однофакторного дисперсионного анализа ANOVA c post-hoc-тестом по Даннетту; при ненормальном распределении - с помощью непараметрического критерия Краскела-Уоллиса c posthос-тестом по Данну. Числовые данные, приведенные на рисунках, представлены в виде $\mathrm{M} \pm \mathrm{SE}$. Анализ главных компонент выполнен с помощью приложения для MS Excel XLStat 2016 (Addinsoft; Франция).

\section{РЕЗУЛЬТАТЫ ИССЛЕДОВАНИЯ}

\section{Выживаемость животных и гистоморфологические изменения печени при экспериментальной НАЖБП}

В течение 6 месяцев эксперимента произошла гибель приблизительно 40\% мышей контрольной и опытных
A

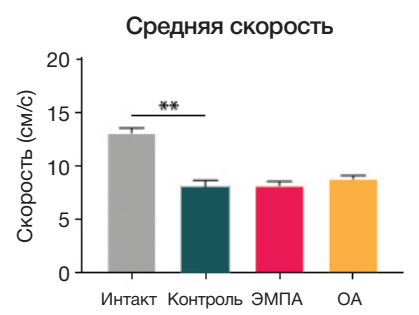

Б

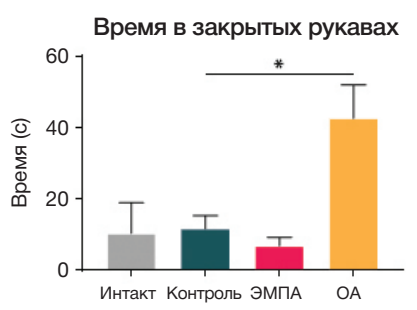

B

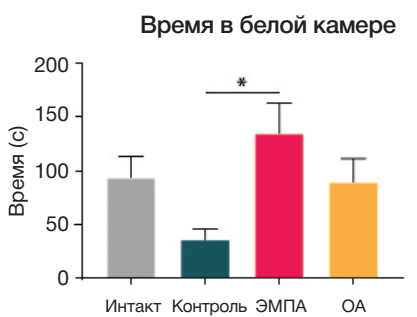

Тест «Открытое поле»
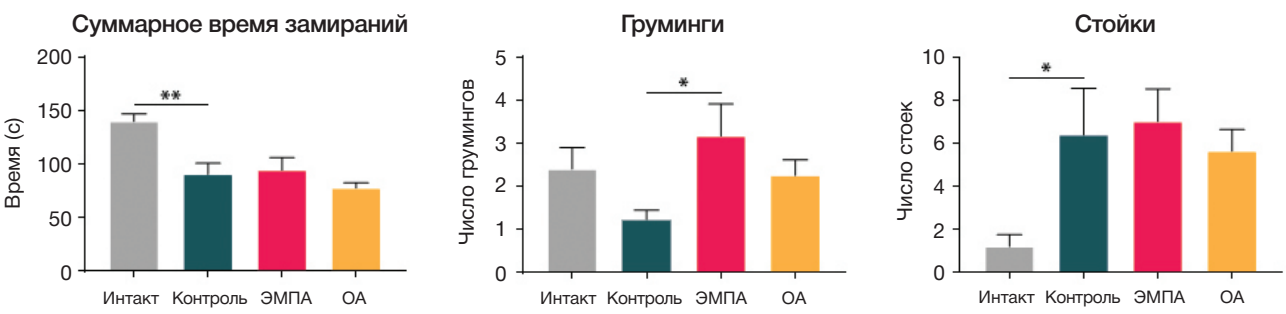

Тест «Приподнятый крестообразный лабиринт»
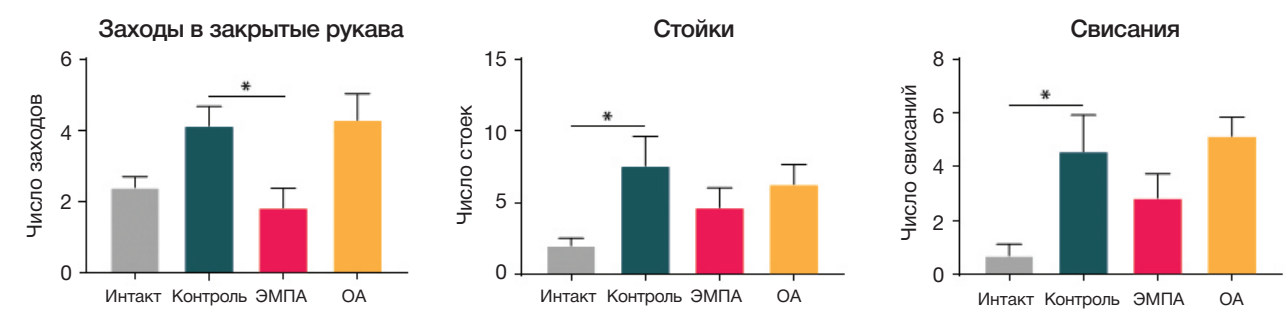

Тест «Черно-белая камера»
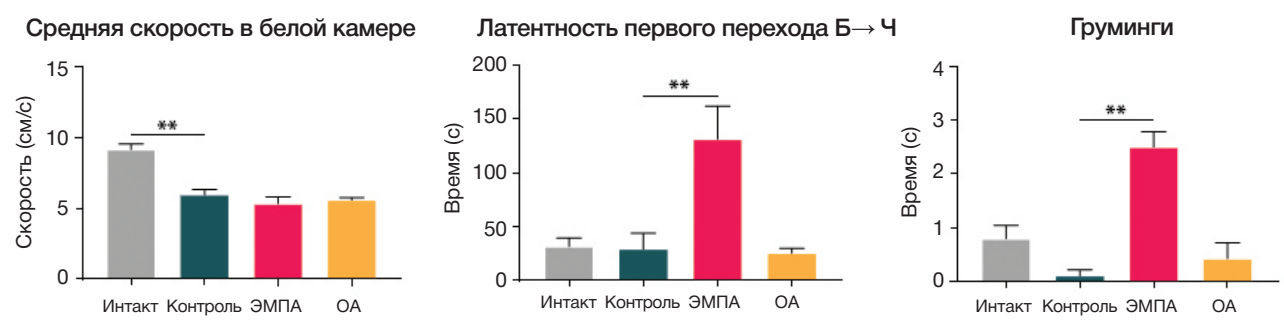

Рис. 2. Результаты оценки поведения мышей в тестах «Открытое поле» (А), «Приподнятый крестообразный лабиринт» (Б) и «Черно-белая камера» (В). ${ }^{*}-p<0,05 ;{ }^{* *}-p<0,01$ 
групп. Ни эмпаглифлозин, ни ОА не оказывали влияния на выживаемость животных (рис. 1Б). Гистоморфологическая картина изменений печени мышей с НАЖБП характеризовалась наличием жировой и баллонной дистрофии гепатоцитов, а также инфильтрацией полиморфноядерными лейкоцитами паренхимы печени. Степень выраженности указанных морфологических изменений была максимальной у животных из контрольной группы: жировой дистрофии были подвергнуты не менее 30\% гепатоцитов, баллонной дистрофии - не менее 30\% гепатоцитов, а также выявлена очаговая инфильтрация полиморфноядерными лейкоцитами. Тестируемые препараты снижали выраженность данных изменений у экспериментальных животных (рис. 1В).

\section{Влияние экспериментальной НАЖБП на исследуемые показатели животных контрольной группы}

При тестировании животных было показано, что развитие стеатогепатита приводит к изменениям поведения, когнитивной функции и физической работоспособности. В тесте ОП мыши с экспериментальной НАЖБП передвигались с меньшей скоростью $(-38 \% ; p<0,01)$, имели меньшее суммарное время замираний $(-35 \%$; $p<0,01)$, а также совершали большее число стоек (+432\%; $p<0,05)$ по сравнению со здоровыми животными (рис. 2А). У контрольной группы было также увеличено число стоек $(+279 \%$; $p<0,05)$ и свисаний $(+553 \% ; p<0,05)$ в ПКЛ (рис. 2Б). В тесте ЧБК, как и в ОП, мыши с НАЖБП передвигались медленнее (-35\%; $p<0,01)$, чем здоровые животные (рис. 2В).

Несмотря на то что в ЛБ у животных всех экспериментальных групп динамика обучения была схожей (уменьшение количества ошибок и времени, затрачиваемого на поиск target box), только у контрольной группы отмечали увеличение как затрачиваемого времени
(+108\%), так и числа ошибок на 12-й день по сравнению с 5-м (+439\%) ( $0<0,05$ в обоих случаях) (рис. 3).

Время вынужденного плавания $(-50 \% ; p<0,05)$, а также время плавания в исходной точке в тесте ТПП (-69\%; $p<0,05)$ были меньше у мышей с НАЖБП без лечения по сравнению с интактной группой. Кроме того, во время ТПП физическая работоспособность мышей контрольной группы восстанавливалась медленнее и их результаты в точке 5 мин уступали результатам здоровых животных $(-63 \% ; p<0,05)$ (рис. 4).

\section{Влияние эмпаглифлозина на исследуемые показатели у животных}

В тесте ОП эмпаглифлозин увеличивал количество грумингов (+160\%; $p<0,05)$ (рис. 2A), а в тесте ПКЛ уменьшал число заходов в закрытые рукава в сравнении с контрольной группой $(-56 \% ; p<0,05)$ (см. рис. 2Б). В тесте ЧБК мыши, получавшие препарат, дольше находились в белой камере $(+275 \% ; p<0,05)$, позднее совершали первый переход в черную камеру $(+355 \% ; p<0,01)$, а также значительно чаще делали груминги по сравнению с контрольными животными (+2173\%; $p<0,01)$ (см. рис. 2В).

Введение эмпаглисллозина мышам с НАЖБП не оказывало статистически значимого влияния на показатели краткосрочной и долгосрочной памяти в ЛБ и физическую работоспособность в тестах ВП и ТПП.

\section{Влияние L-орнитина L-аспартата на исследуемые показатели у животных}

В тестах ОП, ЧБК и ЛБ ОА не оказывал значимого влияния на показатели экспериментальных животных. В тесте ПКЛ он увеличивал время, проводимое животными в открытых рукавах, по сравнению с контрольной группой (+267\%; $p<0,05)$ (рис. 2Б).

Тест «Лабиринт Барнс»

Время нахождения target box

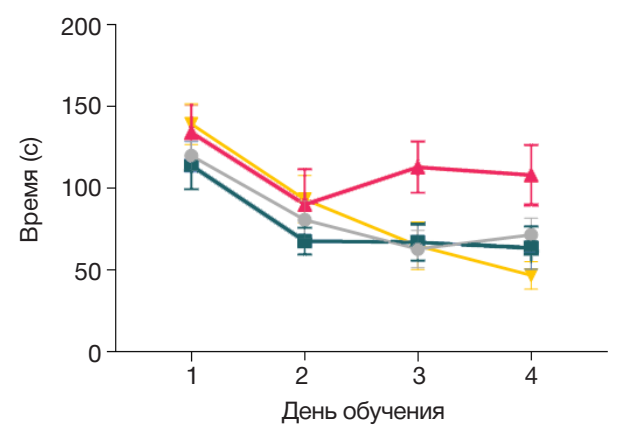

Время нахождения target box

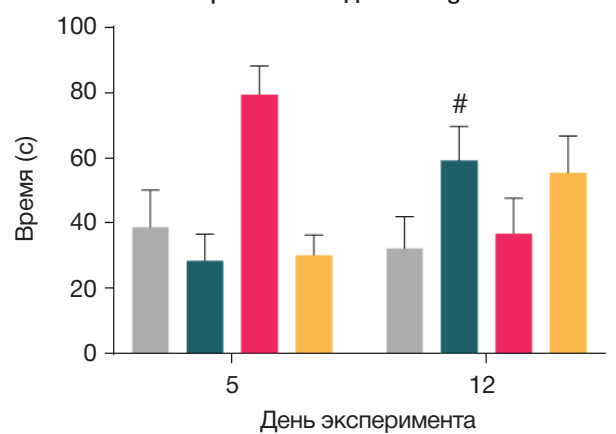

Ошибки при нахождении target box

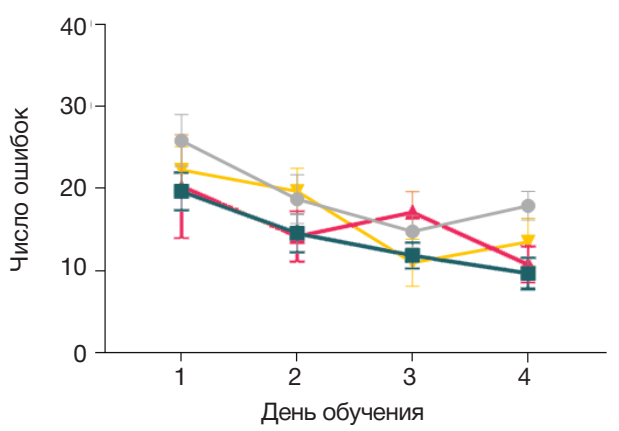

Ошибки при нахождении target box

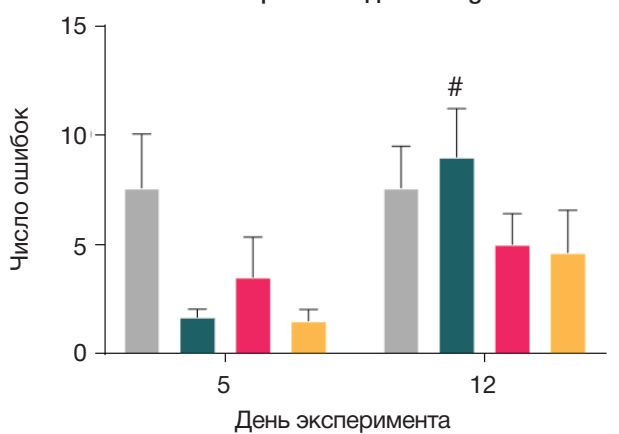

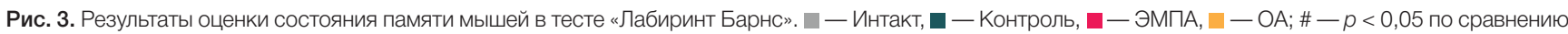
с результатом на 5-й день 
У животных, получавших ОА, время вынужденного плавания было существенно выше, чем в контрольной группе (+106\%; $p<0,05)$, и сопоставимо с результатами здоровых особей. Аналогичным образом в тесте ТПП через 45 мин от исходной точки группа ОА дольше оставалась на поверхности воды в сравнении с группой НАЖБП (+137\%; p 0 0,01) (рис. 4).

\section{ОБСУЖДЕНИЕ РЕЗУЛЬТАТОВ}

В настоящем исследовании изучено влияние курсового введения эмпаглифллозина и ОА на поведение, память и физическую работоспособность мышей линии C57BL/6 c НАЖБП на стадии стеатогепатита.

В тестах ОП и ПКЛ мыши с экспериментальной НАЖБП совершали больше стоек, нежели контрольные животные, а в ПКЛ, кроме того, больше свисаний с открытых рукавов. Увеличение частоты стоек можно рассматривать как признак тревожного состояния животных $[17,18]$. Свисание с открытых рукавов не только является элементом исследовательской активности, но и входит в число действий, совершаемых грызунами для оценки риска [19]. В связи с этим увеличение частоты свисаний само по себе - неоднозначный признак. С учетом одновременного увеличения частоты стоек, а также некоторой склонности животных к посещению закрытых рукавов это изменение может быть расценено как признак повышения тревожности [20, 21].

В тесте ЧБК мыши с НАЖБП, В отличие от интактной группы, реже совершали груминги, при этом была тенденция к снижению времени нахождения в белой камере. Предпочтение грызунами темного закрытого пространства, основанное на проявлении норкового рефлекса, свидетельствует о повышении уровня тревожности [22]. Увеличение тревожности у грызунов на фоне диет-индуцированной НАЖБП в своих исследованиях отмечали и другие авторы [23, 24]. Помимо этого, повышенная тревожность наряду с ухудшением настроения и апатией относится к характерным психоневрологическим симптомам у пациентов, страдающих НАЖБП [3, 6].

Стоит отметить, что у животНЫХ с НАЖБП происходило снижение средней скорости передвижения по сравнению с интактными животными в тестах ОП и ЧБК (в ПКЛ данный показатель не фиксировали), на которое эмпаглифлозин и ОА не оказывали влияния. Кроме того, в ОП у мышей с НАЖБП во всех группах наблюдали уменьшение суммарного времени замирания. Можно предположить,

A

Тест «Вынужденное плавание»

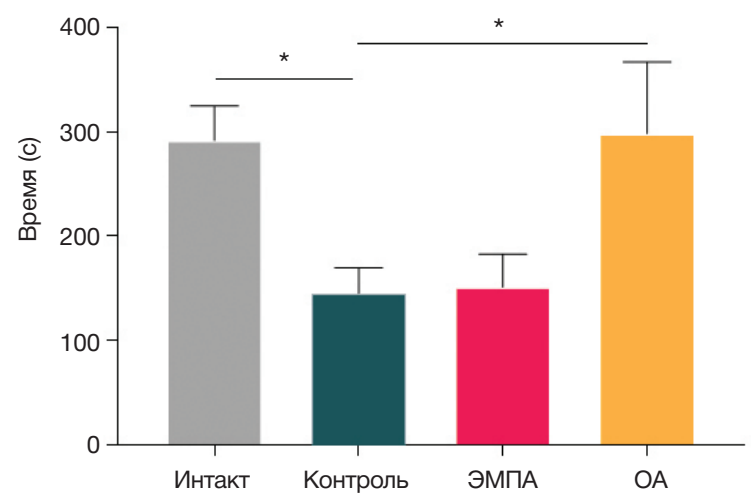

что снижение средней скорости передвижения также является проявлением тревожного поведения. Что касается уменьшения времени замираний, то в классическом понимании данное изменение поведения свидетельствует об анксиолитическом эффекте. Вместе с тем снижение времени замирания может говорить и о том, что мыши активно искали укрытие ввиду повышенной тревожности. Мы решили обратить внимание на данные показатели отдельно ввиду сложности их однозначной интерпретации. Не исключено также, что НАЖБП у мышей вызывает более комплексные изменения поведения, которые нельзя трактовать только с точки зрения увеличения/уменьшения уровня тревожности.

Мыши, получавшие эмпаглифлозин, проводили больше времени в белой камере в тесте ЧБК по сравнению с контрольными животными. Очевидно, при помещении в белую камеру животные испытывали меньшие дискомфорт и потребность в поиске убежища, благодаря чему у них значительно возрастала латентность первого посещения черной камеры. Кроме того, во время своего пребывания в белой камере мыши, получавшие эмпаглифрлозин, совершали больше грумингов, чем контрольные животные. Аналогичное увеличение частоты грумингов было отмечено и в тесте ОП. В настоящее время этот эффект рассматривают двояко. С одной стороны, под воздействием стрессорных факторов животные склонны совершать более частые, но более короткие акты груминга, что наряду с учащением вегетативных (экскреторных) реакций служит признаком повышения тревожности. В данном случае груминг замещает другие поведенческие реакции и виды активности, подавляемые при остром стрессе [25]. С другой стороны, грызуны осуществляют больше грумингов, когда чувствуют себя в безопасности, находятся в спокойном состоянии и не испытывают тревоги [26]. С учетом предпочтения открытого и освещенного пространства увеличение частоты грумингов в данном случае следует расценивать скорее как проявление анксиолитического эффекта препарата.

Описанные нами эффекты эмпаглифлозина могут быть напрямую связаны с его благоприятным влиянием на морфологию глиальных клеток [27], а также с увеличением уровня BDNF (нейротрофический фактор мозга; brain-derived neurotrophic factor) у мышей с ожирением и инсулинорезистентностью [28]. Это дает основание предполагать, что у эмпаглифлозина есть дополнительные центральные механизмы, опосредующие его анксиолитический эффект.

Б Тест «Трехнагрузочная плавательная проба»

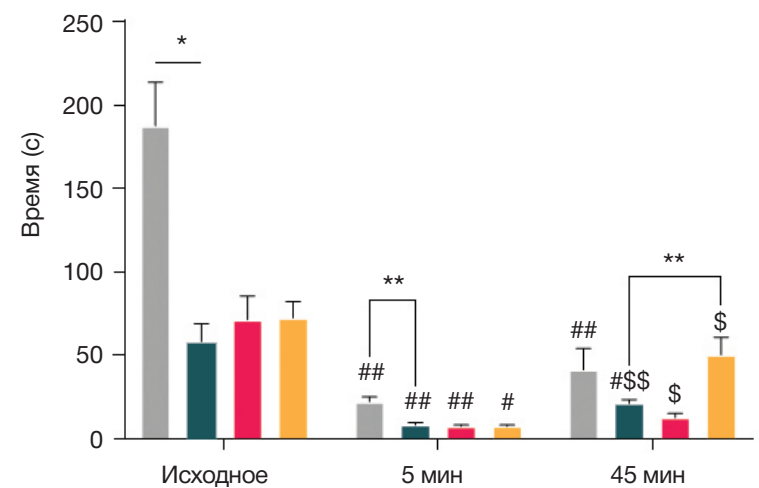

Рис. 4. Результаты оценки физической работоспособности мышей в тестах «Вынужденное плавание» (А) и «Трехнагрузочная плавательная проба» (Б). - Интакт, - Контроль, - - ЭМПА, - ОА; * $-p<0,05 ;{ }^{* \star}-p<0,01 ;$ \# - p<0,05; \#\# - p<0,01 по сравнению с исходным результатом; \$ $p<0,05, \$ \$ p<0,01$ по сравнению с результатом через 5 мин 
ОА у мышей с НАЖБП в тесте ПКЛ увеличивал время нахождения в открытых рукавах, что служит признаком его анксиолитической активности. Отсутствие изменений таких показателей, как частота заходов в закрытые рукава, а также число свисаний с открытых рукавов, может говорить о сохранении спонтанной двигательной и исследовательской активности у животных этой группы [29].

В ЛБ в процессе обучения у животных всех экспериментальных групп снижалось время, затрачиваемое на поиск target box, а также количество совершаемых при этом ошибок. Контрольная группа была единственной, где на 12-й день эксперимента результаты как по времени поиска, так и по количеству ошибок были достоверно хуже, чем на 5-й день. Предположительно, это говорит об ухудшении долговременной памяти у мышей на фоне НАЖБП. Ранее нарушения пространственной памяти были обнаружены у крыс с НАЖБП [30]. Экспериментально установлено, что снижение когнитивного статуса при НАЖБП коррелирует с уменьшением объема серого и белого вещества мозга, а также сопровождается снижением массы мозга в целом [31]. Неалкогольный стеатогепатит и фиброз печени, особенно его поздние стадии, приводят к развитию множественного очагового поражения белого вещества вне зависимости от наличия сопутствующих заболеваний [32]. В группах мышей, получавших лечение одним из препаратов, а также у интактных животных состояние долговременной памяти не было нарушено.

На 3-й, 4-й и 5-й дни эксперимента мыши, получавшие эмпаглифлозин, показывали несколько худшие результаты по времени поиска в сравнении с животными других групп. Характерно, что эти мыши не стремились к исследованию лабиринта и поиску убежища, а, напротив, предпочитали находиться на открытом пространстве, как правило, выбрав для этого одно из ложных отверстий. Это вполне согласуется с высказанным ранее предположением о наличии у эмпаглифлозина анксиолитического эфффекта, который в данном случае способствовал повышению устойчивости мышей к стрессорным воздействиям (в данном случае - открытому пространству и свету).

Ранее было показано, что перевод животных с обычного рациона питания на высокожировую диету при моделировании НАЖБП вызывает достаточно быстрое (к концу первого месяца) ухудшение функционального состояния, проявляющееся двукратным снижением физической работоспособности [33]. В последующем, с 4-го месяца такого питания начиналось постепенное восстановление работоспособности. Однако в настоящей работе метаболическая нагрузка на организм животных была более жесткой. Именно с этим может быть связано то, что к 6 месяцам моделирования НАЖБП адаптация энергопродуцирующих механизмов к новым условиям существования организма не наступила, и физическая работоспособность животных в плавательном тесте оставалась резко сниженной (45\% от уровня интактной группы по сравнению с полным восстановлением уровня работоспособности к 6-му месяцу моделирования при менее жесткой диете).

Необходимо отметить, что в процессе формирования НАЖБП даже в более мягком режиме было выявлено существенное снижение уровня гликогена в скелетных мышцах (на 33\%) и печени (на 44\%) [33]. Сочетание ВКД с инъекционным введением $\mathrm{CCl}_{4}$, обладающего гепатотоксическим и прооксидантным действиями, позволяет получить у животных выраженные нарушения липидного обмена, сопровождающиеся характерными гистоморфологическими изменениями ткани печени, и вызвать дополнительное ухудшение поведенческо-

\section{PCA3}

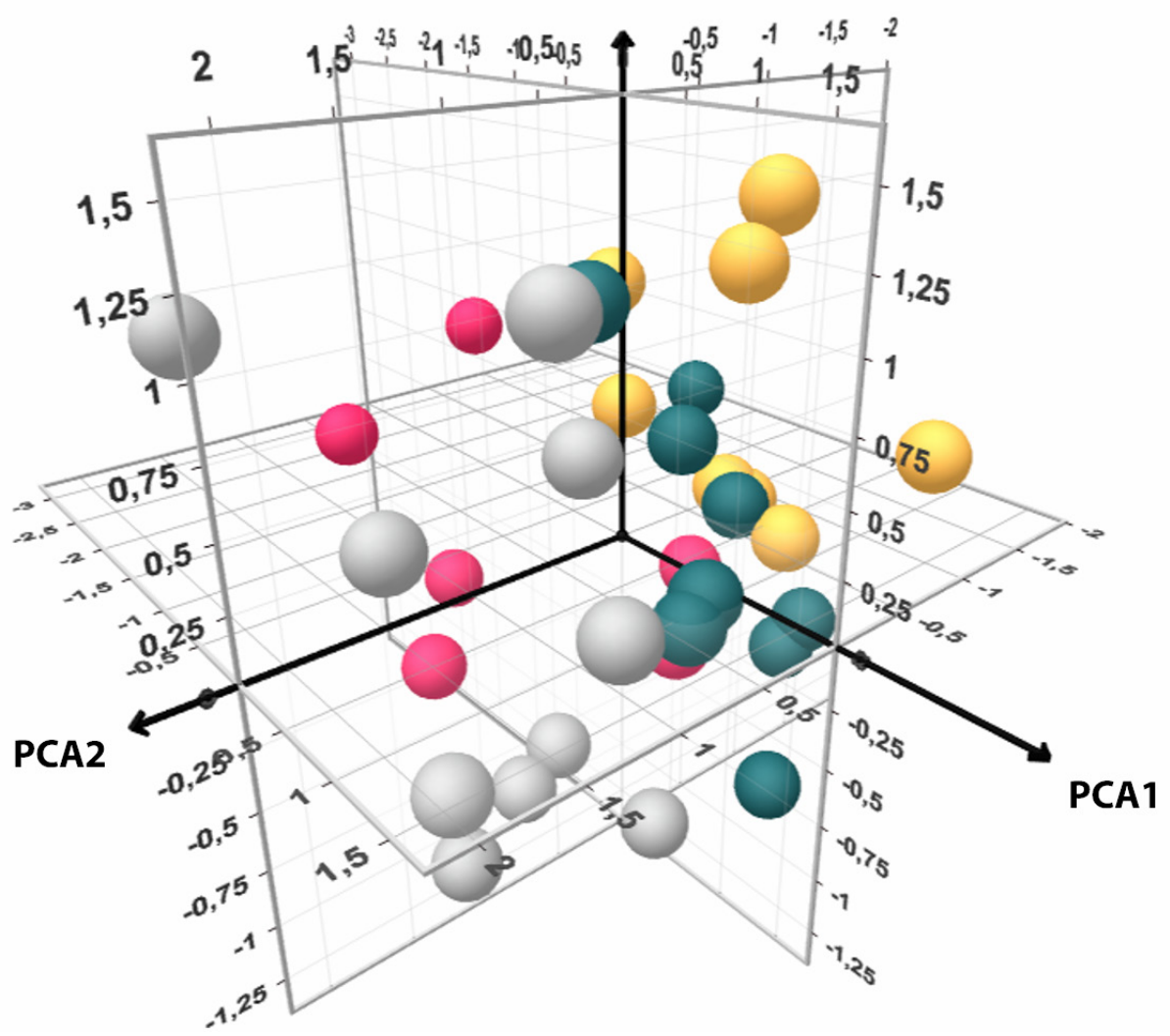

Рис. 5. Графическое представление результатов анализа главных компонент. $\square$ - Интакт, $\mathbf{\square}-$ Контроль, $\mathbf{\square}-$ ЭМПА, $\square-\mathrm{OA}$ 
когнитивных функций и физической работоспособности [12]. Десицит углеводных резервов в скелетных мышцах может быть метаболической основой снижения физической работоспособности лабораторных животных. В настоящем исследовании курсовое применение эмпаглифлозина не оказало влияние на физическую работоспособность животных в тесте вынужденного плавания, что было ожидаемо, так как механизм действия препарата не способствует улучшению транспорта глюкозы в мышцы и усилению синтеза гликогена.

Одним из энергетических резервов для обеспечения мышечной деятельности является распад мышечных белков и включение аминокислот в процессы образования субстратов цикла Кребса. При этом происходит усиленная генерация аммиака, утилизируемого в орнитиновом цикле синтеза мочевины. Известно, что у человека прием ОА активирует цикл мочевины, интенсифицирует липидный обмен, незначительно повышет уровень кетоновых тел и свободных жирных кислот, а также снижает уровень аммиака в крови и субъективное чувство усталости [34]. В нашем исследовании курсовое применение ОА значительно устраняло влияние НАЖБП на фризическую работоспособность животных в тесте вынужденного плавания, что показывает особую роль утилизации аминокислот в энергообеспечении мышечной деятельности при перестройке базового метаболизма организма в условиях ВКД.

Для уточнения механизма действия ОА в отношении физической работоспособности при моделировании НАЖБП была выполнена ТПП. Соотношение значений первой и истощающей нагрузок (сумма первой и второй нагрузок) в группе интактных животных показывает, что причина отказа животных от дальнейшего их выполнения в физическом утомлении при незначительной роли центрального компонента [35]. При моделировании НАЖБП произошло снижение длительности выполнения первой нагрузки в 3 раза, что свидетельствует об уменьшении выносливости; причем высокая утомляемость имеет центральный и периферический компоненты. Курсовое применение эмпаглифлозина и ОА преимущественно снижало центральный, но не периферический компонент, о чем свидетельствовало снижение уровня истощающей нагрузки до 40\% от уровня интактных особей.

Основной показатель ТПП (индекс пробы, ИП) характеризует эффективность механизмов первой фазы восстановления после истощающих нагрузок. Этот показатель равен отношению времени плавания животных с грузом через 45 мин восстановительного периода к длительности истощающей нагрузки. Срочное восстановление распространяется на первые 0,5-1,5 ч отдыха и сводится к устранению накопившихся за период работы продуктов анаэробного распада и погашению кислородного долга. Необходимо отметить, что в срочной фазе постнагрузочного восстановления окислительное фосфорилирование не играет ключевой роли в ресинтезе аденозинтрифосфата (АТФ). Более значим (особенно при истощающих нагрузках, выраженном утомлении и переутомлении, перетренированности) алактатный путь, использующий для ресинтеза АТФ продукт его деградации аденозиндифосфат. Этот механизм запускается высоким уровнем концентрации АДФ в мышцах, который может возникнуть при исчерпании иных путей ресинтеза АТФ. Для обеспечения высокой скорости протекания миокиназной реакции необходима быстрая дальнейшая деградация аденозинмонофосфата АМФ и вывод из скелетных мышц его метаболита - инозинмонофосфата. Именно этот процесс сопряжен с генерацией аммиака активно работающими скелетными мышцами [36].

Оценка ИП показазала, что эмпаглифлозин не влияет на процессы первой фразы восстановления (ИП в интактной группе равен 0,20, в группе ЭМПА-0,19; ИП в контрольной группе равен 0,38 за счет резкого снижения выносливости и связанного с этим малого объема истощающей нагрузки). В то же время при применении ОА ИП был равен 0,61, что свидетельствует о достоверном влиянии препарата на процессы постнагрузочного восстановления. Вероятно, именно с этим может быть связано восстановление физической работоспособности у животных, получавших во время моделирования НАЖБП ОА. Влияние L-орнитина и его различных солей на процессы восстановления (и сопряженное с ними достижение тренировочного эффекта) у здоровых людей и лабораторных животных хорошо известно в практике спортивной медицины [37-39]. Однако его влияние на физическую работоспособность и эфффективность первой фразы процесса восстановления после истощающих нагрузок на фоне формирования НАЖБП показаны впервые.

При анализе всех полученных данных методом главных компонент (principal component analysis, PCA) видно, что животные интактной и контрольной групп имеют выраженные различия, при этом исследуемые препараты оказывают эффект не только за счет влияния на течение НАЖБП, но и имеют собственные, не связанные с данной патологией эффекты (рис. 5). При курсовом введении они могут не только улучшать гистоморфологическую картину печени, но и корригировать симптомы, часто сопровождающие НАЖБП - тревожно-депрессивные расстройства, когнитивные нарушения и астению. Данные эффекты могут иметь большое значение для клинической практики ввиду высокой распространенности НАЖБП среди социально активной части населения.

\section{ВЫВОДЫ}

1. У мышей линии C57BL/6 экспериментальная НАЖБП приводит К выраженным изменениям поведения, проявляющимся главным образом увеличением уровня тревожности. Кроме того, у таких животных ухудшается долговременная память и снижается физическая работоспособность. 2. Курсовое применение эмпаглифлозина и ОА позволяет уменьшить отдельные проявления тревожного поведения и в некоторой степени нормализовать когнитивную функцию. 3. Характерной особенностью ОА является способность корригировать у животных с НАЖБП астению, проявляющуюся снижением физической работоспособности. 


\section{Литература}

1. Younossi ZM. Non-alcoholic fatty liver disease - A global public health perspective. J Hepatol. 2018; 70 (3): 531-44. PubMed PMID: 30414863

2. Ивашкин В. Т., Маевская М. В., Павлов Ч. С., Тихонов И. Н., Широкова Е. Н., Буеверов А. О. и др. Клинические рекомендации по диагностике и лечению неалкогольной жировой болезни печени Российского общества по изучению печени и Российской гастроэнтерологической ассоциации. Российский журнал гастроэнтерологии, гепатологии, колопроктологии. 2016; 26 (2): 24-42.

3. Moretti R, Caruso P, Gazzin S. Non-alcoholic fatty liver disease and neurological defects. Ann Hepatol. 2019; 18 (4): 563-570. PubMed PMID: 31080056.

4. Newton JL. Systemic Symptoms in Non-Alcoholic Fatty Liver Disease. Dig Dis. 2010; 28 (1): 214-9. PubMed PMID: 20460914.

5. Weinstein G, Davis-Plourde K, Himali JJ, Zelber-Sagi S, Beiser AS, Seshadri S. Non-alcoholic fatty liver disease, liver fibrosis score and cognitive function in middle-aged adults: The Framingham Study. Liver Int. 2019; 39 (9): 1713-21. PubMed PMID: 31155826.

6. Youssef NA, Abdelmalek MF, Binks M, Guy CD, Omenetti A, Smith AD, et al. Associations of depression, anxiety and antidepressants with histological severity of nonalcoholic fatty liver disease. Liver Int. 2013; 33 (7): 1062-70. PubMed PMID: 23560860.

7. Chalasani N, Younossi Z, Lavine JE, Charlton M, Cusi K, Rinella M, et al. The diagnosis and management of nonalcoholic fatty liver disease: practice guidance from the American Association for the Study of Liver Diseases. Hepatology. 2018; 67 (1): 328-57.

8. Дударенко С. В., Коваленко А. Л., Прокопенко С. М., Белогурова Е. В. Применение ремаксола в терапии метаболического синдрома у пациентов с неалкогольным стеатогепатитом и сахарным диабетом 2 типа. Экспериментальная и клиническая гастроэнтерология. 2016: 130 (6): 89-94.

9. Маевская М. В., Ивашкин В. Т., Луньков В. Д., Крыжановский С. П., Пирогова И. Ю., Павлов Ч. С. и др. Антиоксиданты в лечении хронических диффузных заболеваний печени (результаты наблюдательной программы «MAXAR»). Российский журнал гастроэнтерологии, гепатологии, колопроктологии. 2018; 28 (5): 77-97.

10. Montgomery MK, Hallahan NL, Brown SH, Liu M, Mitchell TW, Cooney GJ, et al. Mouse strain-dependent variation in obesity and glucose homeostasis in response to high-fat feeding. Diabetologia. 2013; 56 (5): 1129-39. PubMed PMID: 23423668.

11. Almeida-Suhett CP, Graham A, Chen Y, Deuster P. Behavioral changes in male mice fed a high-fat diet are associated with IL-1 $\beta$ expression in specific brain regions. Physiol Behav. 2017; 169: 130-40. PubMed PMID: 27876639.

12. Tsuchida T, Lee AY, Fujiwara N, Ybanez M, Allen B, Martins S, et al. A simple diet- and chemical-induced murine nash model with rapid progression of steatohepatitis, fibrosis and liver cancer. $J$ Hepatol. 2018; 69 (2): 385-95. PubMed PMID: 29572095.

13. Pitts MW. Barnes maze procedure for spatial learning and memory in mice. Bio Protoc [Internet]. 2018 Mar [cited 2020 May 01]; 8 (5): e2744. Available from: https://bio-protocol.org/e2744.

14. Каркищенко Н. Н., Каркищенко В. Н., Шустов Е. Б, Берзин И. А. Капанадзе Г. Д., Фокин Ю. В. и др. Биомедицинское (доклиническое) изучение лекарственных средств, влияющих на физическую работоспособность. Методические рекомендации. М.: Научный центр биомедицинских технологий Федерального медико-биологического агентства, 2017; 134 с.

15. Радько С. В., Гусев К. А., Краснова М. В., Оковитый С. В., авторы; Федеральное государственное бюджетное образовательное учреждение высшего образования «СанктПетербургская государственная химико-фармацевтическая академия» Министерства здравоохранения Российской Федерации (ФГБОУ ВО СПХФА Минздрава России), патентообладатель. Устройство для крепления грузов к мелким лабораторным животным. Патент РФ № 172475. 07.11.2017.

16. Marchesini G, Day CP, Dufour JF, Canbay A, Nobili V, Ratziu V et al. EASL-EASD-EASO Clinical Practice Guidelines for the management of non-alcoholic fatty liver disease. J Hepatol. 2016; 64 (6): 1388-402. PubMed PMID: 27062661.

17. Diaz-Moran S, Estanislau C, Canete T, Blazquez G, Raez A Tobena A et al. Relationships of open-field behaviour with anxiety in the elevated zero-maze test: focus on freezing and grooming. World J Neurosci. 2014; 4: 1-11.

18. Eudave DM, BeLow NM, Flandreau El. Effects of high fat or high sucrose diet on behavioral-response to social defeat stress in mice. Neurobiol Stress. 2018; 9: 1-8. PubMed PMID: 30003122.

19. Sestakova N, Puzserova A, Kluknavsky M, Bernatova I. Determination of motor activity and anxiety-related behaviour in rodents: methodological aspects and role of nitric oxide. Interdiscip Toxicol. 2013; 6 (3): 126-35. PubMed PMID: 24678249.

20. Aduema W, Osim EE, Nwankwo AA. Using the elevated plus maze task in assessing anxiety and fear in swiss white mice. $J$ Complement Med Alt Healthcare [Internet]. 2018 Apr [cited 2020 May 01]; 6 (1): 555678. Available from: https://juniperpublishers. com/jcmah/JCMAH.MS.ID.555678.php.

21. Бахтиярова Ш. К., Капышева У. Н., Аблайханова Н. Т., Баимбетова А. К., Жаксымов Б. И., Корганбаева А. А. и др. Поведение животных в различных тестах. Международный журнал прикладных и фундаментальных исследований. 2017; (8): 92-96.

22. Costall B, Jones BJ, Kelly ME, Naylor RJ, Tomkins DM. Exploration of mice in a black and white test box: validation as a model of anxiety. Pharmacol Biochem Behav. 1989; 32 (3): 77785. PubMed PMID: 2740429.

23. Strekalova T, Evans M, Costa-Nunes J, Bachurin S, Yeritsyan N, Couch $\mathrm{Y}$, et al. Tir4 upregulation in the brain accompanies depression- and anxiety-like behaviors induced by a highcholesterol diet. Brain Behav Immun. 2015; 48: 42-7. PubMed PMID: 25712260.

24. Zemdegs J, Quesseveur G, Jarriault D, Penicaud L, Fioramonti X, Guiard BP. High-fat diet-induced metabolic disorders impairs 5-HT function and anxiety-like behavior in mice. Br J Pharmacol. 2016; 173 (13): 2095-110. PubMed PMID: 26472268.

25. Kalueff AV, Keisala T, Minasyan A, Kuuslahti M, Tuohimaa P. Temporal stability of novelty exploration in mice exposed to different open field tests. Behav Processes. 2006; 72 (1): 104-12. PubMed PMID: 16442749.

26. Kalueff AV, Tuohimaa P. Grooming analysis algorithm for neurobehavioural stress research. Brain Res Brain Res Protoc. 2004; 13 (3): 151-8. PubMed PMID: 15296852.

27. Hayden MR, Grant DG, Aroor AR, DeMarco VG. Empagliflozin ameliorates type 2 diabetes-induced ultrastructural remodeling of the neurovascular unit and neuroglia in the female $\mathrm{db} / \mathrm{db}$ mouse. Brain Sci [Internet]. 2019 Mar [cited 2020 May 01]; 9 (3): 57. Available from: https://www.mdpi.com/2076-3425/9/3/57. PubMed PMID: 30866531.

28. Lin B, Koibuchi N, Hasegawa Y, Sueta D, Toyama K, Uekawa K, et al. Glycemic control with empagliflozin, a novel selective SGLT2 inhibitor, ameliorates cardiovascular injury and cognitive dysfunction in obese and type 2 diabetic mice. Cardiovasc Diabetol. 2014; 13: 148. PubMed PMID: 25344694.

29. Walf AA, Frye CA. The use of the elevated plus maze as an assay of anxiety-related behavior in rodents. Nat Protoc. 2007; 2 (2): 322-8. PubMed PMID: 17406592.

30. Ross AP, Bruggeman EC, Kasumu AW, Mielke JG, Parent MB. Non-alcoholic fatty liver disease impairs hippocampal-dependent memory in male rats. Physiol Behav. 2012; 106 (2): 133-41. PubMed PMID: 22280920.

31. Filipovic B, Markovic O, Duric V, Filipovic B. Cognitive changes and brain volume reduction in patients with nonalcoholic fatty liver disease. Can J Gastroenterol Hepatol [Internet]. 2018 Feb [cited 2020 May 01]; 2018: 9638797. Available from: https:// www.hindawi.com/journals/cjgh/2018/9638797/. PubMed PMID: 29682494.

32. Petta S, Tuttolomondo A, Gagliardo C, Zafonte R, Brancatelli, Cabibi $\mathrm{D}$, et al. The presence of white matter lesions is associated with the fibrosis severity of nonalcoholic fatty liver disease. Medicine (Baltimore) [Internet]. 2016 Apr [cited 2020 May 01]; 95 
(16): e3446. Available from: https://journals.Iww.com/md-journal/ fulltext/2016/04190/ The_Presence_of_White_Matter_Lesions_ Is_Associated.35.aspx. PubMed PMID: 27100443.

33. Оковитый С. В., Шустов Е. Б., Белых М. А., Кириллова Н. В., Спасенкова О. М., Иванов А. Г. и др. Моделирование неалкогольного стеатоза печени: особенности метаболических изменений в организме лабораторных животных. Биомедицина. 2018; (4): 29-43.

34. Sugino $T$, Shiri $T$, Kajimoto $Y$, Kajimoto O. L-ornithine supplementation attenuates physical fatigue in healthy volunteers by modulating lipid and amino acid metabolism. Nutr Res. 2008; 28 (11): 738-43. PubMed PMID: 19083482.

35. Каркищенко В. Н., Каркищенко Н. Н., Шустов Е. Б., Берзин И. А. Фокин Ю. В., Алимкина О. В. Особенности интерпретации показателей работоспособности лабораторных животных по плавательным тестам с нагрузкой. Биомедицина. 2016; (4):

\section{References}

1. Younossi ZM. Non-alcoholic fatty liver disease - A global public health perspective. J Hepatol. 2018; 70 (3): 531-44. PubMed PMID: 30414863.

2. Ivashkin VT, Mayevskaya MV, Pavlov ChS, Tikhonov IN, Shirokova YeN, Buyeverov AO, et al. Diagnostics and treatment of non-alcoholic fatty liver disease: clinical guidelines of the Russian Scientific Liver Society and the Russian gastroenterological association. Russian Journal of Gastroenterology, Hepatology, Coloproctology. 2016; 26 (2): 24-42.

3. Moretti R, Caruso P, Gazzin S. Non-alcoholic fatty liver disease and neurological defects. Ann Hepatol. 2019; 18 (4): 563-570. PubMed PMID: 31080056.

4. Newton JL. Systemic Symptoms in Non-Alcoholic Fatty Liver Disease. Dig Dis. 2010; 28 (1): 214-9. PubMed PMID: 20460914.

5. Weinstein G, Davis-Plourde K, Himali JJ, Zelber-Sagi S, Beiser AS, Seshadri S. Non-alcoholic fatty liver disease, liver fibrosis score and cognitive function in middle-aged adults: The Framingham Study. Liver Int. 2019; 39 (9): 1713-21. PubMed PMID: 31155826.

6. Youssef NA, Abdelmalek MF, Binks M, Guy CD, Omenetti A, Smith AD, et al. Associations of depression, anxiety and antidepressants with histological severity of nonalcoholic fatty liver disease. Liver Int. 2013; 33 (7): 1062-70. PubMed PMID: 23560860.

7. Chalasani N, Younossi Z, Lavine JE, Charlton M, Cusi K, Rinella M, et al. The diagnosis and management of nonalcoholic fatty liver disease: practice guidance from the American Association for the Study of Liver Diseases. Hepatology. 2018; 67 (1): 328-57.

8. Dudarenko SV, Kovalenko AL, Prokopenko SM, Belogurova EV. The use of remaxol in the treatment of metabolic syndrome in patients with nonalcoholic steatohepatitis and diabetes mellitus 2 type. Experimental \& Clinical Gastroenterology. 2016: 130 (6): 89-94.

9. Mayevskaya MV, Ivashkin VT, Lunkov VD, Kryzhanovskiy SP, Pirogova IYu, Pavlov CS et al. Antioxidants in the treatment of chronic diffuse liver diseases (the results of the "MAXAR" observational program). Russian Journal of Gastroenterology, Hepatology, Coloproctology. 2018; 28 (5): 77-97.

10. Montgomery MK, Hallahan NL, Brown SH, Liu M, Mitchell TW, Cooney GJ, et al. Mouse strain-dependent variation in obesity and glucose homeostasis in response to high-fat feeding. Diabetologia. 2013; 56 (5): 1129-39. PubMed PMID: 23423668.

11. Almeida-Suhett CP, Graham A, Chen Y, Deuster P. Behavioral changes in male mice fed a high-fat diet are associated with IL-1 $\beta$ expression in specific brain regions. Physiol Behav. 2017; 169: 130-40. PubMed PMID: 27876639.

12. Tsuchida T, Lee AY, Fujiwara N, Ybanez M, Allen B, Martins S, et al. A simple diet- and chemical-induced murine nash model with rapid progression of steatohepatitis, fibrosis and liver cancer. $J$ Hepatol. 2018; 69 (2): 385-95. PubMed PMID: 29572095.

13. Pitts MW. Barnes maze procedure for spatial learning and memory in mice. Bio Protoc [Internet]. 2018 Mar [cited 2020 May 01]; 8 (5): e2744. Available from: https://bio-protocol.org/e2744.

14. Karkishchenko NN, Karkishchenko VN, Shustov EB, Berzin IA Kapanadze GD, Fokin YuV et al. Biomeditsinskoe (doklinicheskoe)
34-46.

36. Banister EW, Cameron BJC. Exercise-induced hyperammonemia: peripheral and central effects. Int J Sports Med. 1990; 11 (Suppl 2): S129-42. PubMed PMID: 2193891.

37. Demura S, Yamada T, Yamaji S, Komatsu M, Morishita K. The effect of L-ornithine hydrochloride ingestion on human growth hormone secretion after strength training. Advances in Bioscience and Biotechnology. 2010; 1 (1): 7-11.

38. Оковитый С. В., Радько С. В., Краснова М. В. Экспериментальная оценка влияния L-орнитина L-аспартата на физическую работоспособность. Лечебная физкультура и спортивная медицина. 2017; 4 (142): 25-33.

39. Родичкин П. В., Пономарев Г. Н., Пупков П. В., Орлов А. С. Оптимизация силовой подготовленности спортсменов с применением гепатопротекторов. Теория и практика физической культуры. 2019; (10): 89-91.

izuchenie lekarstvennykh sredstv, vliyayushchikh na fizicheskuyu rabotosposobnost'. Metodicheskie rekomendatsii. M.: Nauchnyy tsentr biomeditsinskikh tekhnologiy Federal'nogo medikobiologicheskogo agentstva, 2017; 134 p. Russian.

15. Radko SV, Gusev KA, Krasnova MV, Okovityy SV, inventors; Saint Petersburg State Chemical Pharmaceutical University (SPCPU), assignee. Ustroystvo dlya krepleniya gruzov k melkim laboratornym zhivotnym. Russian Federation patent № 172475. 07.11.2017. Russian.

16. Marchesini G, Day CP, Dufour JF, Canbay A, Nobili V, Ratziu V et al. EASL-EASD-EASO Clinical Practice Guidelines for the management of non-alcoholic fatty liver disease. J Hepatol. 2016; 64 (6): 1388-402. PubMed PMID: 27062661.

17. Diaz-Moran S, Estanislau C, Canete T, Blazquez G, Raez A, Tobena A et al. Relationships of open-field behaviour with anxiety in the elevated zero-maze test: focus on freezing and grooming. World J Neurosci. 2014; 4: 1-11

18. Eudave DM, BeLow NM, Flandreau El. Effects of high fat or high sucrose diet on behavioral-response to social defeat stress in mice. Neurobiol Stress. 2018; 9: 1-8. PubMed PMID: 30003122.

19. Sestakova N, Puzserova A, Kluknavsky M, Bernatova I. Determination of motor activity and anxiety-related behaviour in rodents: methodological aspects and role of nitric oxide. Interdiscip Toxicol. 2013; 6 (3): 126-35. PubMed PMID: 24678249.

20. Aduema W, Osim EE, Nwankwo AA. Using the elevated plus maze task in assessing anxiety and fear in swiss white mice. J Complement Med Alt Healthcare [Internet]. 2018 Apr [cited 2020 May 01]; 6 (1): 555678. Available from: https://juniperpublishers. com/jcmah/JCMAH.MS.ID.555678.php.

21. Bakhtiyarova ShK, Kapysheva UN, Ablaykhanova NT, Baimbetova AK, Zhaksymov BI, Korganbaeva AA, et al. Povedenie zhivotnykh $v$ razlichnykh testakh. Mezhdunarodnyy zhurnal prikladnykh i fundamental'nykh issledovaniy. 2017; (8): 92-96. Russian.

22. Costall B, Jones BJ, Kelly ME, Naylor RJ, Tomkins DM. Exploration of mice in a black and white test box: validation as a model of anxiety. Pharmacol Biochem Behav. 1989; 32 (3): $777-$ 85. PubMed PMID: 2740429.

23. Strekalova T, Evans M, Costa-Nunes J, Bachurin S, Yeritsyan N, Couch $\mathrm{Y}$, et al. TIr4 upregulation in the brain accompanies depression- and anxiety-like behaviors induced by a highcholesterol diet. Brain Behav Immun. 2015; 48: 42-7. PubMed PMID: 25712260

24. Zemdegs J, Quesseveur G, Jarriault D, Penicaud L, Fioramonti X, Guiard BP. High-fat diet-induced metabolic disorders impairs $5-\mathrm{HT}$ function and anxiety-like behavior in mice. Br J Pharmacol. 2016; 173 (13): 2095-110. PubMed PMID: 26472268.

25. Kalueff AV, Keisala T, Minasyan A, Kuuslahti M, Tuohimaa P. Temporal stability of novelty exploration in mice exposed to different open field tests. Behav Processes. 2006; 72 (1): 104-12. PubMed PMID: 16442749.

26. Kalueff AV, Tuohimaa P. Grooming analysis algorithm for neurobehavioural stress research. Brain Res Brain Res Protoc. 
2004; 13 (3): 151-8. PubMed PMID: 15296852.

27. Hayden MR, Grant DG, Aroor AR, DeMarco VG. Empagliflozin ameliorates type 2 diabetes-induced ultrastructural remodeling of the neurovascular unit and neuroglia in the female $\mathrm{db} / \mathrm{db}$ mouse. Brain Sci [Internet]. 2019 Mar [cited 2020 May 01]; 9 (3): 57. Available from: https://www.mdpi.com/2076-3425/9/3/57. PubMed PMID: 30866531.

28. Lin B, Koibuchi N, Hasegawa Y, Sueta D, Toyama K, Uekawa K, et al. Glycemic control with empagliflozin, a novel selective SGLT2 inhibitor, ameliorates cardiovascular injury and cognitive dysfunction in obese and type 2 diabetic mice. Cardiovasc Diabetol. 2014; 13: 148. PubMed PMID: 25344694

29. Walf AA, Frye CA. The use of the elevated plus maze as an assay of anxiety-related behavior in rodents. Nat Protoc. 2007; 2 (2): 322-8. PubMed PMID: 17406592.

30. Ross AP, Bruggeman EC, Kasumu AW, Mielke JG, Parent MB. Non-alcoholic fatty liver disease impairs hippocampal-dependent memory in male rats. Physiol Behav. 2012; 106 (2): 133-41. PubMed PMID: 22280920

31. Filipovic B, Markovic O, Duric V, Filipovic B. Cognitive changes and brain volume reduction in patients with nonalcoholic fatty liver disease. Can J Gastroenterol Hepatol [Internet]. 2018 Feb [cited 2020 May 01]; 2018: 9638797. Available from: https:// www.hindawi.com/journals/cjgh/2018/9638797/. PubMed PMID: 29682494

32. Petta S, Tuttolomondo A, Gagliardo C, Zafonte R, Brancatelli, Cabibi $\mathrm{D}$, et al. The presence of white matter lesions is associated with the fibrosis severity of nonalcoholic fatty liver disease. Medicine (Baltimore) [Internet]. 2016 Apr [cited 2020 May 01]; 95
(16): e3446. Available from: https://journals.Iww.com/md-journal/ fulltext/2016/04190/ The_Presence_of_White_Matter_Lesions_ Is_Associated.35.aspx. PubMed PMID: 27100443.

33. Okovitiy SV, Shustov EB, Belyh MA, Kirillova NV, Spasenkova OM, Ivanov AG, et al. Modeling of non-alcoholic liver steatosis: features of metabolic changes in the body of laboratory animals. Biomedicine. 2018; (4): 29-43.

34. Sugino T, Shiri $T$, Kajimoto $Y$, Kajimoto O. L-ornithine supplementation attenuates physical fatigue in healthy volunteers by modulating lipid and amino acid metabolism. Nutr Res. 2008; 28 (11): 738-43. PubMed PMID: 19083482.

35. Karkischenko VN, Karkischenko NN, Shustov EB, Berzin IA, Fokin YuV Alimkina OV. Features interpretation of laboratory animal health indicators in swimming tests with load. Biomedicine. 2016; (4): 34-46.

36. Banister EW, Cameron BJC. Exercise-induced hyperammonemia: peripheral and central effects. Int J Sports Med. 1990; 11 (Suppl 2): S129-42. PubMed PMID: 2193891

37. Demura S, Yamada T, Yamaji S, Komatsu M, Morishita K. The effect of L-ornithine hydrochloride ingestion on human growth hormone secretion after strength training. Advances in Bioscience and Biotechnology. 2010; 1 (1): 7-11.

38. Okovity SV, Radko SV, Krasnova MV. Experimental assessment of influence of L-ornithine-L-aspartate on physical efference. Lechebnaya fizkul'tura i sportivnaya meditsina. 2017; 4 (142): 25-33.

39. Rodichkin PV, Ponomarev GN, Pupkov PV, Orlov AS. Hepatoprotectors to build strength in athletes. Theory and Practice of Physical Culture. 2019; (10): 89-91. 